\title{
Periapical granuloma: radiological, histopathological, and bacteriological examination
}

\author{
Helme A Al - TAEE * \\ Abbas F Al - TAEE ** \\ Mahmood Y TAHA***
}

\begin{abstract}
Fifty patients with periapical granuloma were studied. Radiological examination showed radiolucent lesion associated with the root apex less than $1 \mathrm{~cm}$ in diameter. Histological examination of the lesion showed typical features of priapical granuloma as described by by WHO. While bacteriologically, periapical granuloma was sterile .
\end{abstract}

Key Words: Periapical granuloma, histopathological,examination, lesions.

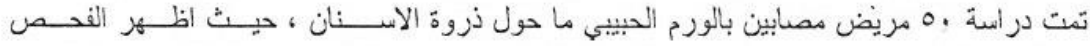

الشعاعي آفات شفافة مرتبطة بذروة الجذر وبقطر انقل من (1) سم ، كما اظهر الفحص النسيجي للآفة صـورة

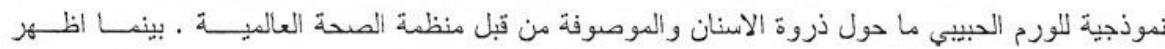

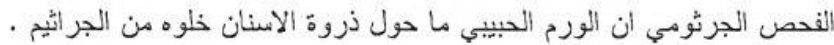

\section{INTRODUCTION}

Periapical granuloma is a focal inflammatory cells and reactive elements attached to the tooth root. The lesion occurs in response to a variety of irritants that reach periapical tissue via root canal (1). Periapical granuloma may persist for long time without symptoms, but without apparent cause, it may become acute and the associated tooth either sound or badly carious ${ }^{(2)}$.

Radiologically, the earliest periapical change in the periodontal ligament appear as thickening of the ligament at the apex of the root. As the granulation tissue proliferated and continued concomitant resorption of the bone, the periapical granuloma appears as radiolucent area of variable sizes attached to the root apex ${ }^{(3)}$.

*Helme A AL - TAEE; BDS, MSc: Lecturer. Department of Oral and Maxillofacial Surgery, College of Dentistry, University of Mosul, Mosul, IRAQ.

**Abbas F AL - TAEE; BDS, MSc: Lecturer. Department of Oral and Maxillofacial Surgery, College of Dntistry, University of Mosul, Mosul, IRAQ.

***Mahmood Y TAHA; BVM\&S, MSc, PhD, MlB: Assistant Prof. Department of Basic Sciences,

College of Dentistry, University of Mosul, Mosul, IRAQ. 
Histologically, the periapical granuloma tissue consists of polymorph nuclear leukocytes, plasma cells, fibroblasts and capillaries. Epithelial cells may persist in some granulomas ${ }^{(4,5,6)}$.

The bacteriological finding in periapical granuloma is still controversy. Some researchers showed that periapical granuloma was infected with various types of microorganisms like sterpococci, staphylococci, gram positive bacilli especially the center of the granuloma ${ }^{(7)}$. Others showed that periapical granuloma was sterile lesion ${ }^{(6)}$

The aim of this study is to establish a good diagnosis by definitive clinical and radiological examination of the accused tooth and to confirm this by histopathlogical examination. The study also includes the bacteriological basis of the lesion.

\section{MATERIALS AND METHODS}

Fifty-eight patients, attended the Department of the Oral and Maxillofacial Surgery complaining from periapical lesions, were selected for this study. Those patients were of both sexes and have age range between $(19-43)$ years old.

Patients were (19) to have periapical lesions on the clinical and radiological basis. Radiological examination was carried out in the unit of Radiology, Department of Oral and Maxilliofacial Surgery. The criteria used for selection of patients were:

1. The size of periapical lesion is not more than $1 \mathrm{~cm}$ in diameter.

2. No intra or extra- oral sinus associated with accused teeth.

3. Absence of abscess or inflammation around the offending tooth with healthy gum.

4. Patients should be medically healthy.

5. Only the six upper anterior teeth were included.

6. Cases diagnosed histopathologically as periapical granuloma were included; others were excluded

All patients were treated by periapical surgery including apicectomy and/or retrograde filling by amalgam. Every patient was prepared before surgical procedures. Chlorhexidine gluconate $0.2 \%(\mathrm{w} / \mathrm{v})$ mouthwash was used three times for (48) hours before treatment in order to minimize the number of pathogenic microorganism in the oral cavity and to decrease the chance of contamination by oral microflora.

All surgical instruments were sterilized before surgery either by hot air oven or autoclave. A protective measure was used like face-mask, disposable gloves and antiseptic solution to clear the circumoral immediately after giving local anesthesia.

Following local anesthesia, the flap was raised and bone was exposed and the periapical lesion was localized and removed. A swab was then taken from the lesion using sterile stick and immersed into brain heart infusion broth and incubated at $37 \mathrm{C}^{\circ}$ for half an hour. The incubated swab was then cultured on different media (blood agar, chocolate agar, MacConkey agar, sabauroud agar) at $37 \mathrm{C}^{\circ}$ under aerobic and anaerobic conditions. The above culture media were prepared according to the manufacturer instructions. Positive control micro-organisms were cultured on the same media to check the conditions and media used.

Bacteriological examination was carried out in the unit of Clinical Microbiology.

Periapical lesion was then interested into a small bottle containing formaline and processes for histopathological examination. The latter was carried out in the Department of Oral Diagnosis and Periodontology. 


\section{RESULTS}

The total number of patients was 58 ( 25 males and 33 females), eight cases were excluded because histopathological examination showed periapical cysts and abscess. The remaining (50) were (21) males and (29) females. The age of the patients ranges between (19) and (43). Thirty four patients had equal or less than (25) years old and the remaining ( 16 patients) were more than $(25)$ years old. The types of teeth included were (20) central incisors, (24) lateral incisors and (6) canines. The results of this study are presented in table (1).

Table (1): Shows the distribution of patients according to age, sex, type of tooth and results of different examinations

\begin{tabular}{|c|c|c|c|c|}
\hline 188 & & & & 10121 \\
\hline $25=$ & 34 & & & \\
\hline $25=$ & 16 & & & 50 \\
\hline Sex & $F=29$ & $M=21$ & & 50 \\
\hline $1 / y 00$ or 100011 & $\mathrm{UCI} / 20$ & ULI/24 & $\mathrm{UC} / 6$ & 50 \\
\hline 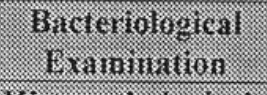 & $\begin{array}{c}- \text { ve } \\
\text { growth/48 }\end{array}$ & + ve growth/2 & & 50 \\
\hline 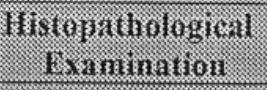 & $\begin{array}{c}\text { Typical P.A.G. } \\
50 \\
\end{array}$ & & $\begin{array}{c}\text { Other P.A. } \\
\text { lesions/8 excluded }\end{array}$ & 50 \\
\hline 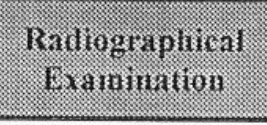 & \multicolumn{4}{|c|}{$\begin{array}{l}\text { Shows various types of P.A. radiolucencies ranging from } \\
\text { slight increase in the thickness of P.A. space to well } \\
\text { localized radiolucency less than } 1 \mathrm{~cm} \text {. in diameter. }\end{array}$} \\
\hline
\end{tabular}

Radiological examination showed different degree of radiolucencies ranging from slight increase in the thickness of the periodontal space to well localized radiolucency reaching a maximum diameter of (1) $\mathrm{cm}$. Concerning the histopatological examination, (58) biopsies were examined, only (50) showed a typical periapical granuloma (inflammatory cells, collagen fibers, fibroblasts and small capillaries).

Bacteriological examination of (50) cases showed negative results in (48) cases which means that the lesion (periapical granuloma) was sterile. Only two cases showed positive bacteriological growth of Satphylococcus epidermidis which is probably due to contamination of the swab.

\section{DISCUSSION}

The histopathological results indicate that periapical granuloma essentially consists of an oedematous moderately collagenous connective tissue infiltrated by variable number by lymphocytes, plasma cells, large mononuclears and polymorph nuclear leukcytes. Five cases show the presence of epithelial cells (epithelial rest of malazes) within the lesion indicating that the origin of periapical cyst is from priapical granuloma. 
Periapical granuloma is classified as either epitheliated or non- epitheliated ${ }^{(8)}$. Most investigators had shown that approximately (50\%) of granulomas are epitheliated ${ }^{(6,9)}$. Our results are accord with them.

The radiographical description of periapical granuloma is the same as shown by others ${ }^{(3)}$. The radiographical results indicate the abscess, granuloma and cyst can not be differentiated on the radiographical basis. The apical lesion measures approximately $(0.5)$ inches in diameter, which was formerly through as granuloma, abscess or cyst must simply be considered as evidence of bone changes in the region of the root apex. Such explanation is in agreement with others ${ }^{(10,11)}$

The bacteriological findings of this study indicate that periapical granuloma is sterile lesion. Periapical granuloma is regarded as a defense mechanism but this defense power of the granuloma is inadequate ${ }^{(6)}$. The presence of growth in two cases probably due to environmental contamination as the bacterial growth is not on the sreaking line. Block et $a^{(3)}$ examined 230 biopsy specimens from periapical granuloma, only (24) specimens showed bacterial growth and the remaining were sterile. Cook ${ }^{(4)}$ investigated the bacterial contents of a number of granulomas and showed that non-hemolytic streptococci was the predominate organism, while others $^{(2)}$ showed the $(22)$ cases out of $(34)$ were sterile and the remaining were infected. They were able to isolate bacteria only when suppuration had taken place in the lesion.

\section{REFERENCES}

1. Al-Taee HA, Zaidan HA. A comparative study between the use of different techniques used in the treatment of anterior teeth with periapical lesion. MSc thesis submitted to the College of Dentistry, Baghdad University, 1992.

2. Brich RH, Meliville TH, Neubert EW. A comparison of root canal and apical lesion flora ; problems of direct bacteriological sampling of the periapical lesion. Brit Dent J. 1964;116: 350-352.

3. Block RM, Bushell A, Rodrignes H, Langeland KA. Histopathologic, bacteriologic and radiographical study of periapical endodontic surgical specimens. Oral Surg Oral Med Oral Pathol. 1976; 42: 656-678

4. Cook TJ. Dental granuloma. J Am Dent Assoc. 1927; 14: 223.

5. Freeman N. Histopathological investigation of the dental granuloma. J Dent Res. $1931 ; 11: 175-200$.

6. Freeman N. Histopathological investigation of the dental granuloma. J Dent Res. 1981; Vol. XI, No. 2.

7. Grossman LI. Bacteriological status of periapical tissue in 150 cases of infected pulpless teeth. J Dent Res. 1959; 38:101-104.

8. Hill TJ. The epithelium in dental granuloma. J Dent Res. 1930; 10: 323.

9. Yanagisawa S. Pathological study of periapical lesions 1. Periapical granuloma: clinical histopathological and immunohistopathological studies. J Oral Pathol. 1980; 9: 288- 300 .

10. Wuehrmann AH, Manson-Hing LR. Dental Radiology. $5^{\text {th }}$ Edn. CV Mosby Co. St Louis. 1981; Pp: 322.

11. Stafne EC, Gibilisco JA. Oral Roentagenographic Diagnosis $3^{\text {rd }}$ Edn. Philadelphia,WB. Saunders Co. 1969. 


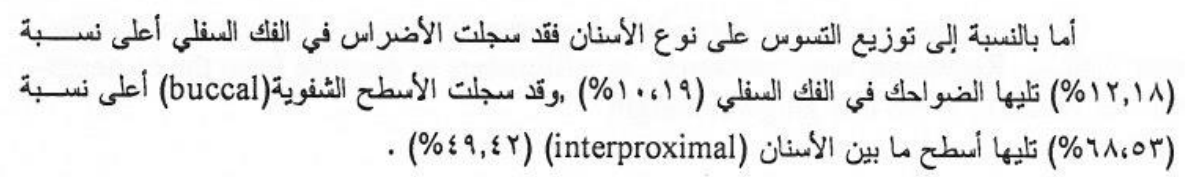

\section{INTRODUCTION}

Gingival recession is an important problem affecting almost all older adults to some degree ${ }^{(1)}$. In the U.S.A. gingival recession has been reported to occur in $(78 \%$ $100 \%)$ of middle aged individual, in (22\% -53\%) of the teeth, and in $(19 \%-40 \%)$ of tooth surfaces ${ }^{(2-5)}$. In Germany, gingival recession occurred in $(76 \%-87 \%)$ of middle - aged subjects and $(32 \%-63 \%)$ of all teeth ${ }^{(6)}$.

A root caries lesion is initiated on root surface exposed to the oral environment, such exposures is therefore, a pre-requisite for this type of decay.

The Root Caries Index (RCI), a proposed index to report root caries, was first presented at the (1979) meeting of the International Association for Dental Research $(\mathrm{LADR})$ in New Or leans ${ }^{(7)}$.

The (RCI) measured the root surfaces as either having recession present with signs of dental caries (filled or decayed) for having recession present with no signs of dental caries (sound surface). The keystone of (RCI) equation is to eliminate the root surfaces with out recession. So the (RCI) represents a measurement that can be readily understood (e.g. the percent of teeth at risk attacked by disease), can be reported by tooth (like the DMF index) or by tooth surface (like the DMFS index) and reported either by person at risk or by tooth type.

The purpose of this study was to investigate the prevalence and intraoral distribution of root caries using Root Caries Index (RCI) in the adult population age $(30-70)$ years in Mosul city -Iraq .

\section{MATERIALS AND METHODS}

A random sample of 1270 subjects were collected with an age ranged from 30 70 years, taken from the city of Mosul from a random eight different factories, eight secondary schools, seven primary schools and five collage from the University of Mosul.

The examination of the root surface caries as well as gingival recession was carried out using plane mouth mirror and sickle shaped explorer. All subjects were examined while seated in a side chair, the examination was carried out in a suitable room under natural daylight.

The criteria described by Benting et $\mathrm{al}^{(8)}$ for the identification of root caries were used. The Root Caries Index (RC I) was calculated for each subject as follow ${ }^{(9)}$.

$$
R C I=\frac{(R-D)+(R-F)}{(R-D)+(R-F)+(R-N)} \times 100
$$

Where root surfaces scored as follows: R-D: Recession with decayed root surface R-F: Recession with a filled root surface. R-N: Recession with a sound root surface. 
Gingival recession was recorded as present if at least $0.5 \mathrm{~mm}$ of root surface was visible. Recession was measured in millimeters as distance from the cementoenamel Junction to the free gingival margin ${ }^{(10)}$.

\section{Statistical analysis:}

The analysis in this study include the following:-

1- Calculation of statistical parameters the mean, standard deviation and percentage.

2- Analysis of data by using Chi-square test to determine significant differences between males and females.

3- Analysis of variance followed by Duncan's Multiple Range Test were used to determine the significant differences among the age groups.

The differences were considered significant when the probability $(p)$ level equal to or less than $0.05(p<0.05)$.

\section{RESULTS}

Distribution of the sample by age and 'gender are shown in table (1). The sample consists of 1270 subjects, 719 males ( $56.6 \%$ ) and 551 females ( $43.4 \%)$.

The sample is divided into four age groups, namely, 30-39, $40-49,50-59$ and 60-69 years .

Table(1): Distribution of the sample by age

\begin{tabular}{|c|c|c|c|c|c|c|}
\hline \multicolumn{2}{|c|}{ 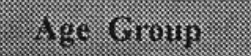 } & \multicolumn{2}{|c|}{ Males: } & ininglos & \multicolumn{2}{|c|}{ Bot: } \\
\hline (Const) & No. & $\%$ & 1.0. & $\%$ & Ni: & 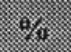 \\
\hline 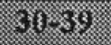 & 141 & 36.43 & 246 & 63.57 & 387 & 100 \\
\hline 40,19 & 233 & 53.56 & 202 & 40.44 & 435 & 100 \\
\hline .53 .53 & 245 & 72.70 & 92 & 27.30 & 337 & 100 \\
\hline 63.69 & 100 & 90.09 & 11 & 9.91 & 111 & 100 \\
\hline Tonat & 719 & 56.61 & 551 & 43.39 & 1270 & 100 \\
\hline
\end{tabular}

Table (2) shows the mean percentage of ( $\mathrm{RCI}$ ) rates by age and gender. The result reveals that the mean $(\mathrm{RCI})$ in the age group (30-39) years is $(21.12 \%)$, while in other age group decrease significantly and reported $(5.22 \%, 3.88 \%$ and $6.27 \%$ ) respectively . 
Table (2): Distribution of root surface caries index ( $\mathrm{RCI}$ ) according to the type o teeth.

\begin{tabular}{|c|c|c|c|c|}
\hline 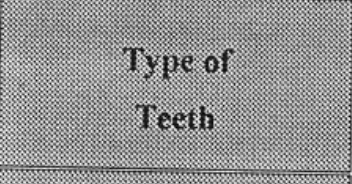 & 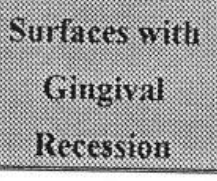 & 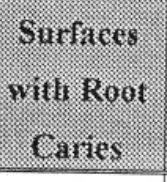 & 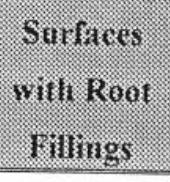 & $(\%), 140$ \\
\hline Haxilany Molar, & 3282 & 213 & 6 & $6.25 \pm 0.136$ \\
\hline Matillary, Prentolin: & 2374 & 129 & 2 & $5.22 \pm 0.068$ \\
\hline Whillime linisors and & 2422 & 37 & 8 & $1.82 \pm 0.008$ \\
\hline Mandibular Molars & 3920 & 533 & 11 & $12.18 \pm 0.412$ \\
\hline Mandibular frentolar & 2723 & 304 & 5 & $10.19 \pm 0.314$ \\
\hline 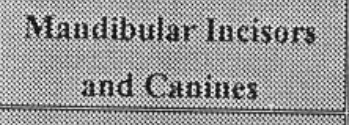 & 4529 & 55 、 & 2 & $1.24 \pm 0.001$ \\
\hline 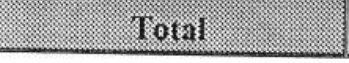 & 19250 & 1271 & 34 & $6.34 \pm 0.828$ \\
\hline
\end{tabular}

Over all the (R C I ) rates is slightly higher in females ( $7.77 \%$ ) than in males ( $5.71 \%)$ and these differences are statistically insignificant .

The intraoral distribution of (RCI) is shown in table (3). The mandibular molars constantly exhibits the highest score rate of R C I $(12.18 \%)$, followed by mandibular premolars $(10.19 \%)$, while the maxillary and mandibular incisors and canines are less likely to be affected $(1.82 \%$ and $1.24 \%)$ respectively.

Table (3): Distribution of root surface caries on different tooth surfaces.

\begin{tabular}{|c|c|c|c|c|c|c|}
\hline \multirow{2}{*}{$\begin{array}{l}\text { Type of } \\
\text { Tedili: }\end{array}$} & \multicolumn{2}{|c|}{ Siricial } & \multicolumn{2}{|c|}{$\begin{array}{l}\text { Lingunis } \\
\text { Sumposes }\end{array}$} & \multicolumn{2}{|c|}{ Interproximal: } \\
\hline & No: & $8 \%$ & No. & \%. & $\mathrm{N}_{0 .}$ & $\%$ \\
\hline Maxillay, Miolans & 142 & 66.67 & 4 & 1.88 & 67 & 31.45 \\
\hline Masillary Iremiolats & 69 & 53.49 & 3 & 2.39 & 57 & 44.19 \\
\hline 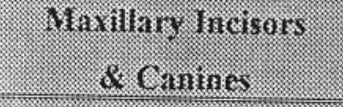 & 33 & 89.18 & 2 & 5.41 & 2 & 5.41 \\
\hline Mrnablowhar Malars & 404 & 75.80 & 9 & 1.69 & 120 & 22.51 \\
\hline 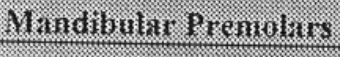 & 183 & 60.20 & 6 & 1.97 & 115 & 37.83 \\
\hline $\begin{array}{l}\text { Mindibular Incisons } 0 \\
\text { Crmines }\end{array}$ & 40 & 72.73 & 2 & 3.64 & 13 & 23.63 \\
\hline Iratal & 871 & 68.53 & 26 & 2.05 & 374 & 29.42 \\
\hline
\end{tabular}


The distribution of root surface caries on different tooth surfaces is shown in table (4). The study indicated that the majority of root surface caries is found on the facial surfaces ( $68.53 \%$ ) followed by the interproximal surfaces $(29.42 \%)$, while the lingual surfaces less likely to be affected with root surface caries $(2.05 \%)$.

Table (4): Age - specific mean RCI rates and standard deviation by gender.

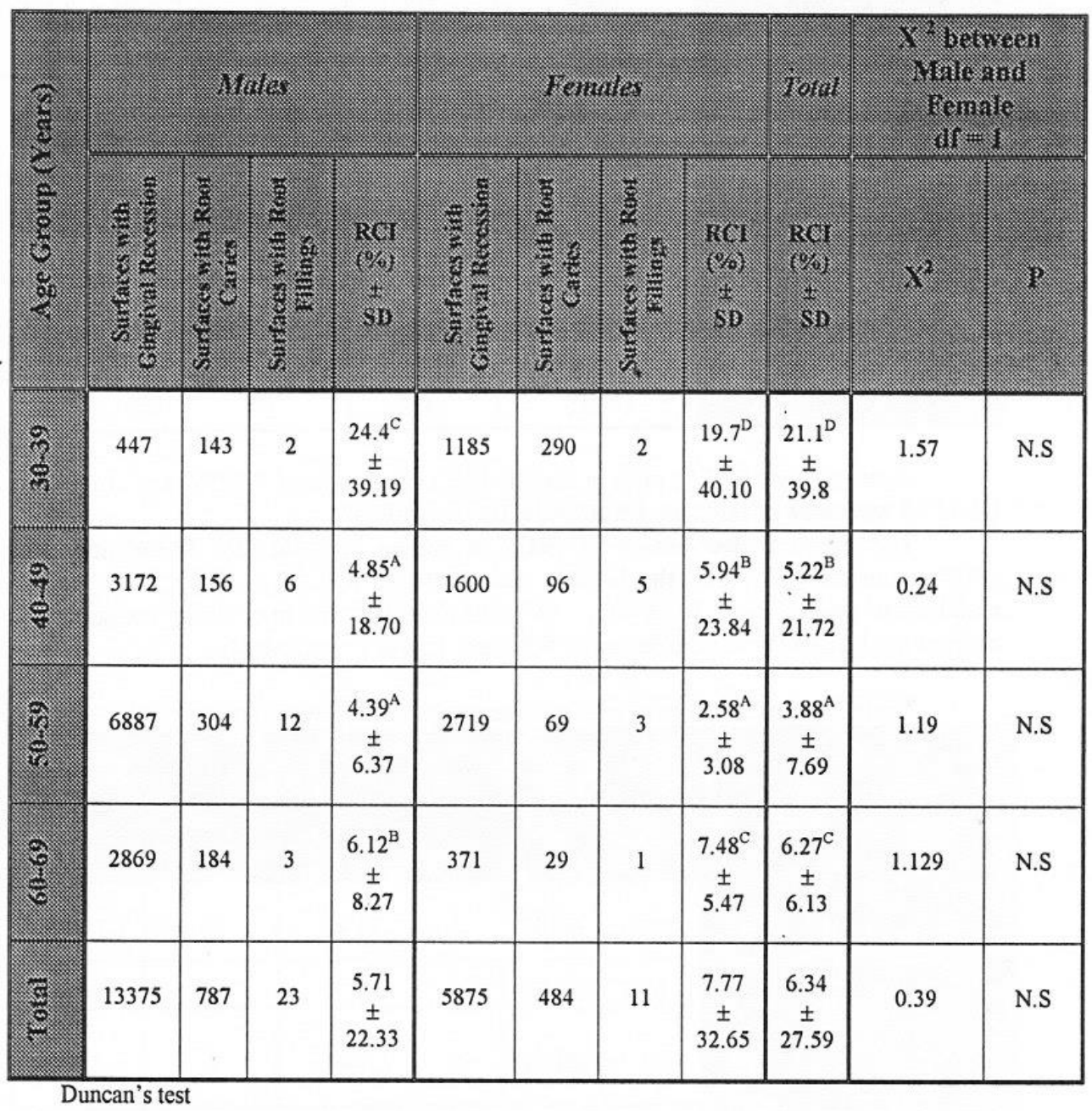

- $\mathrm{RCI}$ with the same letter within the subgroup is statistically insignificant.

\section{DISCUSSION}

Most of the studies in epidemiology etiology, prevention and treatment of caries have directed to the coronal caries in which an initial lesion is in enamel and most of these have confined to children and young adults because of high caries activity. 
Root surface caries has been and continued to be a major problem for dentate elderly adults. As such management of a root caries in older population is predicated to be one of the greatest challenges facing dental team in the future ${ }^{(11)}$

In order to provide specific preventive regimes and improved treatment for root surface lesions, it is essential this data are collected and the prevalence and the distribution of the disease are estimated.

The study revealed that the over all Root Caries Index (RCI) was (6.34\%); i.e, one out of every fifteen surfaces with recessions.

The mean percentage of (RCI) for subjects aging (30-39) years is higher than the older age groups. These differences are statistically significant. These finding disagree with the findings of other studies ${ }^{(12-16)}$. In all these studies the RCI rate tended to increase with age, in contrast to other measures of disease frequency, this trend is not maintained into the older age group.

If the rate of increase of gingival recession is decreasing with age, then there will be a decrease in the prevalence of root caries in the older age group ${ }^{(17)}$. These differences in RCI in this study could be attributed to the fact that the age group (3039) years reported large number of root surface caries with small number of surfaces with gingival recession in comparing with other age groups, while age group (60-69) years shows higher number of surfaces with gingivat recession in which the recession increase with age ${ }^{(18)}$.

As for sex difference the total females recorded higher RCI rate $(7.77 \%)$ than that recorded by the total males $(5.71 \%)$; however, there was no statistical significant difference between them. These findings disagree with study by Katz et al ${ }^{(19)}$

Also these differences could be due to the fact that in this study, total females reported small number of surfaces with gingival recession. This fact due to that females look after their teeth better than males ${ }^{(20,21)}$ so females have better gingival
condition ${ }^{(22,23)}$.

The study indicated that there were very low number of surfaces with root filling in comparison to high number of surfaces with root decay for the total sample, these findings are in agreement with other Iraqi study ${ }^{(15)}$, while it was contrast to the findings in studies carried out in developed countries ${ }^{\text {(10,24-27) }}$.

The high need of restorative treatment for these adults reflect the limited dental awareness regarding the importance of dental health and limited utilization of dental services.

The intraoral distribution of $(\mathrm{RCI})$ rates according to the type of teeth revealed that the mandibular molars and premolars recorded higher (RCI) rates $(12.18 \%)$ and $(10.19 \%)$ respectively, followed by those of maxillary molars and premolars $(6.25 \%$ and $5.22 \%$ ) respectively, while the maxillary incisors and canines $(1.82 \%)$ and the mandibular incisors and canines $(1.24 \%)$ was less effected. This study has been shown that root caries tends to primarily effect mandibular molars and premolars with a decreasing susceptibility to incisors. These findings are in agreement with other studies ${ }^{(3,15,19)}$. This could be attributed to the fact mandibular posterior teeth have less surface with gingival recession than that did anterior ones, this agree with the reported of other studies ${ }^{(28,29)}$, where as it opposite to the results of ${ }^{(6,30)}$, and as these result the mandibular teeth are more likely to be affected with root surface caries than maxillary
teeth.

The study has displayed that the majority of the teeth surfaces affected with root surface caries are the facial surfaces followed by the interproximal surfaces for 
all tooth types and the lingual surfaces are seldom involved. These findings are in agreement with other studies $(15,16,19,24)$.

The facial surfaces contributed the highest percentage of root surface caries, this could be due to the higher tendency of facial surfaces to be more exposed to the oral environment like plaque and calculus accumulation ${ }^{(24,31)}$, as a result the root surfaces of the facial surfaces become more exposed and the gingival recession being very prevalent ${ }^{(32)}$.

On the other hand, the most persistent positive factor could be due to high occurrence of gingival recession in such surfaces because of the positive relation between a gingival recession and an incorrect tooth brushing technique ${ }^{(32)}$, in which most of the people here concentrate on improper use of tooth brush especially on these easier surfaces, where as lingual surfaces are less likely to be affected with gingival recession ${ }^{(32)}$.

The adult population of this sample are need a preventive and curative programs which include dental health education to stimulate individuals to adopt proper oral hygiene habits, this may prevent the progression of periodontal disease and prevent root caries. Also, the use of different types of topical applications of different types of topical applications of fluoride as fluoridated mouth rinses, fluoride dentifrices and fluoride gel to arrest the root caries. In addition, there is a high need for dental treatment for those with very high percentages of untreated root caries.

\section{REFERENCES}

1-Kaumudi J, Joshipura RJ, Kent RV, Paul F, De Paola PF . Gingival recession, intraoral distribution and associated factors. J Periodontol. 1994; 65: 864-871.

2-Gorman W. Prevalence and etiology of gingival recession. J Periodontol. 1967; 38: 316-321.

3-Lohse WG, Carter HG, Bruunell J. The prevalence of root surface caries in a military population. Military Med. 1977; 141: 700 - 703

4-Beck JD, Hand JS, Hunt R J, Field HM. Prevalence of root and coronal caries in a non-institutionalized older population. J Am Dent Assoc. 1985; 111: 964-967.

5-Miller A, Brunekel J, Carlos J, Brown L, Löe H. Oral health of United States adults, National findings. National Institute of Health Research, Bethesda, NIH Publication, No. 87-2868, 1987.

6-Roetzke P, Rockel V. Verteilung Porodonteler Rezessionen und von karies Betroffener. War zelober flochochochen bei patinten Einer zahuklinik. Deusch Zahnorzil Z. 1986; 41 : 765 - 766 (English Abstract).

7-Katz RV. A method for reporting and scoring root caries in epidemiologic studies. $J$ Dent Res. 1979; 58: 379.(Abstract)

8-Banting D, Ellen R, Fillery E, Prevalence of root surface caries among institutionalized older persons. Community Dent Oral Epidemiol. 1980; 8: 84-88.

9-Katz RV. Assessing root caries in populations. The evaluation of root caries index. $J$ Public Health Dent. 1980; 40: 7-16.

10-Locker D, Slade GD, Leake JL. Prevalence and factors associated with root decay in older adults in Canada. J Dent Res. 1989; 68: 768-772.

11-Astroth D. Caring for elderly adult: How to prevent, manage root surface caries. Dental Team Work. 1996; Sept-Oct: 15-20. 
12-Kitanura M, Kiyak H, Mulligan KK. Predictors of root caries in the elderly. Community Dent Oral Epidemiol. 1986; 14: 34-38.

13-Keltjens H, Schacken M, Van der Hoven J, Herdriks J. Epidemiology of root surface caries in patients treated for periodontal disease. Community Dent Oral Epidemiol. 1988; 16: 171-174.

14-Wallace MC, Retief DH, Bradley EL. Prevalence of root caries in a population of older adults. Gerodontol. 1988; 4: 84-89.

15-AL-Weheb A. Prevalence of root surface caries in AL-Taji District. J College of Dent. 1999; 4: 49-58.

16-Fadhi SW. Oral health status and treatment needs among Iraqi factory employees in Baghdad city (a cross sectional study). MSc Thesis Submitted to the College of Dentistry, University of Baghdad. 1999.

17-Banting DW. Epidemiology of root caries .Gerodontol. 1986; 5: 5-11.

18-Winn DM, Brunolle JA, Selwitz RH. Coronal and root caries in dentition of adults in the United States: 1988-1991. J Dent Res. 1996; 75: 642-651.

19-Katz R, Hazen S, Chilton N, Mumma R. Prevalence and intraoral distribution of root caries in an adult population Caries Res. 1982; 16: 265-271.

20-Schou L. Oral health promotion at work sites .Int Dent J. 1989; 39: 122-128.

21-Chen M, Andersen R, Barmes M, et al. Comaring'Oral health care system. A second international collaborative study. World Health Organization, Geneva. 1997.

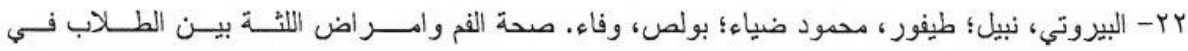

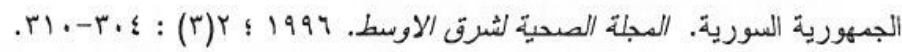

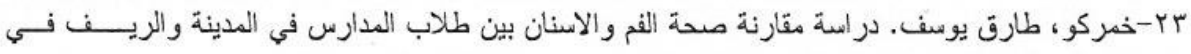

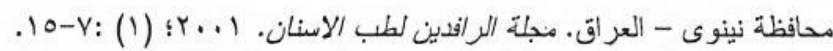

24-Luan WM, Baelam V, Chen M, Fejerskov O. Dental caries in adult and elderly Chinese. J Dent. 1989; 68: 1771-1776.

25-Ravald N, Birkhed D, Hamp S. Root caries susceptibility in periodontally treated patients. Results after 12 years. J Clin Periodontol. 1993; 20: 124-129.

26-Papas AS, Joshi A, Giunta J. Prevalence and intra-oral distribution of coronal and root caries in middle -aged and older adults. Caries Res. 1988; 2(26): 459-465.

27-Narhi TO, Vehkalahti M, Paivi S, Ainamo A. Salivary findings daily medication and root caries in the old elderly. Caries Res. 1998; 32: 5-9.

28-Sangenes G, Gjermo P. Prevalence of oral soft and hard tissue lesions related to mechanical tooth-cleaning procedures. Community Dent Oral Epidemiol.1976; 4: 77 82 .

29-Wilson R. Marginal tissue recession in general practice: A preliminary study. Int $J$ Periodont Restorstive Dent. 1983; 3(1): 40-49.

30-Paloheimo L, Ainamo L, Niemi ML, Vikinkosi M. Prevalence of and factors related to gingiva recession in Finnish 15-20-years old subjects. Community Dent Health. 1987; 4: 25-32.

31-Shay K. Root caries in the older patient: Significance, prevention and treatment. Dent Clin North Am. 1997; 4(4):763 - 793.

32-Vehkalahti M. Occurrence of gingival recession in adults. J Periodontol. 1989; 60: 599-603. 